\title{
Produtividade agroeconômica de mandioquinha-salsa em resposta à adição de cama-de-frango no solo
}

\section{Productivity agro-economic peruvian carrot in response to addition of broiler manure in soil}

\author{
Diego Menani Heid ${ }^{1 *}$; Néstor Antonio Heredia Zárate²; Maria do Carmo Vieira ${ }^{2}$; \\ Elissandra Pacito Torales 3 ; Thiago de Oliveira Carnevali³; Bianca Gabrieli Marafiga ${ }^{4}$
}

\section{Resumo}

O presente trabalho teve como objetivo avaliar a produtividade agroeconômica da mandioquinhasalsa 'Amarela de Carandaí', em resposta a adição de cama-de-frango no solo. Os tratamentos foram o resultado das combinações de doses $\left(1 ; 6 ; 10 ; 14\right.$ e $19 \mathrm{t} \mathrm{ha}^{-1}$ ) e formas de adição ( cobertura e incorporada) de cama-de-frango no solo, determinados utilizando-se a matriz experimental Plan Puebla III. O delineamento experimental utilizado foi blocos casualizados com quatro repetições. Avaliaram-se as massas frescas e secas de folhas, rebentos, coroas, raízes comercializáveis e não-comercializáveis. Também foram contados os números de rebentos, raízes comercializáveis e não-comercializáveis e feito o diâmetro e comprimento de raízes comercializáveis e não-comercializáveis. As maiores produtividades de folhas e coroas $\left(7,97 \mathrm{e} 7,04 \mathrm{t} \mathrm{ha}^{-1}\right)$ obtidas nos tratamentos $19 \mathrm{C}$ e $19 \mathrm{I}, 19 \mathrm{C}$ e $1 \mathrm{I} \mathrm{t}$ ha $^{-1}$ de cama-de-frango, superaram em 47,30 e 35,94\%, aos menores valores obtidos com os tratamentos $6 \mathrm{C}$ e 1 I e $6 \mathrm{C}$ e $14 \mathrm{I} \mathrm{tha}^{-1}$, respectivamente. Massa fresca de raiz comercializável não foi influenciada significativamente pelos fatores em estudo, obtendo a maior média de produtividade $\left(22,08 \mathrm{t} \mathrm{ha}^{-1}\right) \mathrm{e}$ renda líquida ( $\mathrm{R} \$ 43.475,76$ ) com o uso de $19 \mathrm{C}$ e $14 \mathrm{I} \mathrm{t} \mathrm{ha}^{-1}$ de cama-de-frango. O maior comprimento de raízes comercializáveis $(98,16 \mathrm{~mm})$ foi obtido com 9,19 C e 11,56 I t ha ${ }^{-1}$ de cama-de-frango, superando em 50,37 mm ao menor valor obtido com o tratamento $19 \mathrm{C}$ e $1 \mathrm{I} \mathrm{t} \mathrm{ha}{ }^{-1}$. Nas condições em que foi desenvolvido o experimento concluiu-se que as doses e formas de aplicação da cama-de-frango possibilitaram o aumento da produtividade média de raízes comercializáveis, renda bruta e líquida e que para se obter maior renda líquida, o cultivo deve ser feito com adição ao solo de $19 \mathrm{t} \mathrm{ha} \mathrm{a}^{-1} \mathrm{em}$ cobertura e $14 \mathrm{t} \mathrm{ha}^{-1}$ incorporada de cama-de-frango.

Palavras-chave: Arracacia xanthorrhiza, rentabilidade, resíduo orgânico

\begin{abstract}
The aim of this work was to evaluate the agricultural economic yield from Peruvian carrot 'Yellow of Carandaí ', in response to addition of broiler manure on the soil. The treatments were the result of combinations of doses $\left(1,6,10,14\right.$ and $\left.19 \mathrm{tha}^{-1}\right)$ and addition forms (and incorporated coverage) of litter, ground chicken determined using the experimental matrix Plan Puebla III. The experimental design was randomized blocks with four replications. Evaluated the fresh and dry weight of leaves, shoots, crowns, marketable yield and unmarketable. We also counted the numbers of shoots, roots marketable and nonmarketable and made the diameter and length of marketable and non-marketable yield. Highest yields

\footnotetext{
${ }^{1}$ Discente de Doutorado, Universidade Federal da Grande Dourados, UFGD, Dourados, MS. E-mail: diegoheid@hotmail.com

2 Profs., UFGD, Dourados, MS. E-mail: nestorzarate@ufgd.edu.br; mariavieira@ufgd.edu.br

3 Pós Doutorandos, UFGD, Dourados, MS. E-mail: ninapacito@hotmail.com; thiagocarnevali@hotmail.com

${ }^{4}$ M.e, UFGD, Dourados, MS. E-mail: biancamarafiga@hotmail.com

* Autor para correspondência
} 
of leaves and crowns (7.97 and $\left.7.04 \mathrm{t} \mathrm{ha}^{-1}\right)$ were obtained under treatments $19 \mathrm{SA} / 19$ IS and $19 \mathrm{SA} / 1$ IS, respectively, increased to 47.30 and $35.94 \%$ when compared to lowest values by treatments $6 \mathrm{SA} / 1$ IS and6 SA / 14 IS, respectively. Fresh mass of marketable roots was not significantly influenced by the studied factors, its highest average yield $\left(22.08\right.$ ton $\left.\mathrm{ha}^{-1}\right)$ and net income (R\$ 43,475.76) were attained under $19 \mathrm{SA} / 14 \mathrm{IS} \mathrm{t} \mathrm{ha}^{-1}$ of broiler manure. Greatest length of marketable roots $(98.16 \mathrm{~mm})$ was attained under $9.19 \mathrm{SA} / 11.56 \mathrm{IS}$ ton $\mathrm{ha}^{-1}$, increased to $50.37 \mathrm{~mm}$ compared to the smallest one using 19 SA / 1 IS. Thus, under conditions in which the experiment was carried out, it leads to conclude that the combination among doses and addition methods of broiler manure enabled the rise productivity of marketable roots and net income; thereby to obtain higher net income the Peruvian carrot growth should be done by adding broiler manure split as 19 ton ha ${ }^{-1}$ surface applied and $14 \mathrm{tha}^{-1}$ incorporated to the soil.

Key words: Arracacia xanthorrhiza, profitability, organic residue

\section{Introdução}

A mandioquinha-salsa é originária da região andina da América do Sul, encontrando-se plantas, em vales onde a altitude varia de 1.700 a 2.500 $\mathrm{m}$ e as temperaturas médias anuais oscilam entre 15 e $18^{\circ} \mathrm{C}$ (HERMANN, 1997). No Brasil, a mandioquinha-salsa é cultivada principalmente nas regiões Sudeste e Sul, em pequenas áreas, com pouco uso de insumos e mão-de-obra familiar. A área de plantio de mandioquinha-salsa é de aproximadamente 16.000 ha, sendo o Paraná e Minas Gerais os principais Estados produtores, com 7.633 ha e 6.000 ha, respectivamente. Porém o maior volume de comércio é no entreposto da CEAGESP (BUENO, 2004). Em Mato Grosso do Sul, a quantidade disponível nos mercados locais é pequena, por falta de tradição no consumo pela população, fazendo com que essa hortaliça seja oferecida ao consumidor com preços altos e que impedem seu uso nos cardápios de pessoas de baixa renda (HEREDIA ZÁRATE et al., 2008).

Seu produto mais valioso são as raízes, com sua composição centesimal crua de $74 \%$ de água, $101 \mathrm{kcal}$, proteína (1g), carboidratos $(24 \mathrm{~g})$, fibra alimentar (2,1 g), cinzas (1,1 g), Ca (17g), Mg (12 $\mathrm{mg}), \mathrm{Mn}(0,1 \mathrm{~g}), \mathrm{P}(45 \mathrm{mg}), \mathrm{Fe}(0,3 \mathrm{mg}), \mathrm{K}$ (50,5 $\mathrm{mg}), \mathrm{Cu}(0,05 \mathrm{mg}), \mathrm{Zn}(0,2 \mathrm{mg})$, tiamina $(0,05$ $\mathrm{mg})$, piridoxina $(0,12 \mathrm{mg})$ e beta-caroteno $(0,8$ microgramas) (KINUPP; LORENZI, 2014). Embora apresente características favoráveis, o cultivo e a pesquisa de mandioquinha-salsa apresentam-se pouco difundida no Brasil.
A adição de resíduos orgânicos favorece a manutenção da matéria orgânica do solo, melhorando suas propriedades físicas, químicas e biológicas. Do ponto de vista físico, o uso de estercos promove o aumento da estabilidade de agregados, associado à redução da densidade do solo. Com relação às propriedades químicas, destaca-se o aumento da disponibilidade de nutrientes para as culturas e da capacidade de troca de cátions (CTC), associados à complexação de elementos tóxicos. A matéria orgânica também auxilia a atividade dos organismos do solo, o que por sua vez resulta em impactos positivos sobre a ciclagem de nutrientes (KIEHL, 2010).

Melo et al. (2009) citam que em qualquer atividade econômica é essencial o estudo da rentabilidade e o acompanhamento dos custos de produção para a melhor competitividade no mercado, principalmente no meio agrícola, que pode ser fator determinante para o sucesso ou fracasso do produtor. Isso devido a rentabilidade consistir, normalmente, na comparação da receita com o custo de produção, o que determina o lucro. Assim, só haverá lucro se a atividade produtiva proporcionar retorno superior ao custo (SILVA; ANEFALOS; REIS FILHO, 2001). Torales (2012), avaliando a produtividade agroeconômica de mandioquinhasalsa cultivada com dois espaçamentos entre plantas $(20$ e $25 \mathrm{~cm})$ dentro da fileira no canteiro e diferentes formas de adição de cama-de-frango no solo (sem, cobertura, incorporada e cobertura + incorporada), obtiveram as maiores produtividades 
de raízes comercializáveis com a utilização da cama-de-frango na forma incorporada $\left(15,96 \mathrm{tha}^{-}\right.$ $\left.{ }^{1}\right)$ e cobertura + incorporada $\left(12,98 \mathrm{t} \mathrm{ha}^{-1}\right)$, sendo a maior renda líquida ( $\mathrm{R} \$ 34.779,27)$, obtida com a utilização da cama-de-frango incorporada e com espaçamento de $25 \mathrm{~cm}$ entre plantas na fileira.

O presente trabalho objetivou avaliar a produtividade agroeconômica da mandioquinhasalsa 'Amarela de Carandaí', em resposta a doses e formas de adição de cama-de-frango no solo.

\section{Material e Métodos}

O trabalho foi desenvolvido no Horto de Plantas Medicinais, da Faculdade de Ciências Agrárias FCA, da Universidade Federal da Grande Dourados - UFGD, em Dourados - MS, entre abril de 2011 e janeiro de 2012. A área experimental situa-se em latitude de $22^{\circ} 11^{\prime} 44^{\prime}$ 'S, longitude de 54 $56^{\prime} 08^{\prime \prime} \mathrm{W}$ e altitude de $430 \mathrm{~m}$. O clima da região, seguindo classificação Köppen-Geiger, é do tipo Aw (PEEL; FINLAYSON; McMAHON, 2007) com médias anuais para precipitação e temperatura de $1425 \mathrm{~mm}$ e $22^{\circ} \mathrm{C}$, respectivamente. O solo é do tipo Latossolo
Vermelho distroférrico, de textura muito argilosa (EMBRAPA, 1999).

Os fatores em estudo foram cinco doses de cama-de-frango $(1 ; 6 ; 10 ; 14$ e 19 t ha-1) adicionadas ao solo em cobertura e incorporada. Os tratamentos foram determinados utilizando-se a matriz experimental Plan Puebla III (TURRENT; LAIRD, 1975), conforme o esquema apresentado na Figura 1, combinando doses de cama-defrango em cobertura e incorporada, sendo elas, respectivamente: $6 \mathrm{tha}^{-1} \mathrm{em}$ cobertura-C / $6 \mathrm{t} \mathrm{ha}^{-1}$ incorporada-I; $14 \mathrm{t} \mathrm{ha}^{-1} \mathrm{C} / 6 \mathrm{t} \mathrm{ha}^{-1} \mathrm{I} ; 6 \mathrm{tha}^{-1} \mathrm{C} / 14 \mathrm{t}$ ha ${ }^{-1} \mathrm{I} ; 14 \mathrm{t} \mathrm{ha}^{-1} \mathrm{C} / 14 \mathrm{t} \mathrm{ha}^{-1} \mathrm{I} ; 10 \mathrm{t} \mathrm{ha}^{-1} \mathrm{C} / 10 \mathrm{t} \mathrm{ha}^{-1} \mathrm{I}$; $1 \mathrm{t} \mathrm{ha}^{-1} \mathrm{C} / 6 \mathrm{t} \mathrm{ha}^{-1} \mathrm{I} ; 19 \mathrm{t} \mathrm{ha}^{-1} \mathrm{C} / 14 \mathrm{t} \mathrm{ha}^{-1} \mathrm{I} ; 6 \mathrm{tha}^{-1} \mathrm{C}$ / $1 \mathrm{t} \mathrm{ha}^{-1}$ I e $14 \mathrm{t} \mathrm{ha}^{-1} \mathrm{C} / 19 \mathrm{t} \mathrm{ha}^{-1} \mathrm{I}$. O delineamento experimental utilizado foi o de blocos casualizados, com nove tratamentos e quatro repetições. As parcelas foram de 4,5 $\mathrm{m}^{2}$ (1,5 $\mathrm{m}$ de largura por 2,0 $\mathrm{m}$ de comprimento), sendo que a largura efetiva do canteiro foi de $1,0 \mathrm{~m}$, contendo três fileiras de plantas espaçadas em $33,3 \mathrm{~cm}$ e espaçamento entre plantas de $25 \mathrm{~cm}$, perfazendo população de 79.200 plantas $\mathrm{ha}^{-1}$. O preparo do terreno realizouse com uma aração e uma gradagem e posterior levantamento dos canteiros com rotocanteirador.

Figura 1. Tratamentos em estudo e determinados, como resultado das combinações de cinco doses de cama-de-frango em cobertura e cinco doses de cama-de-frango incorporadas no solo, utilizando-se a matriz experimental Plan Puebla III.

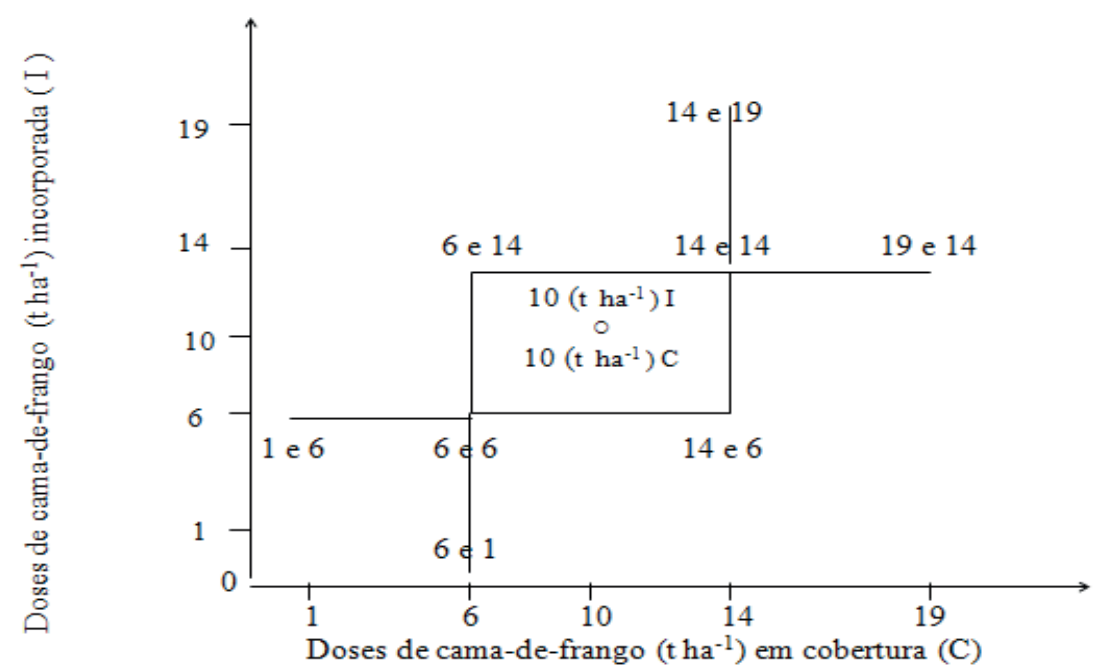

Fonte: (TURRENT; LAIRD, 1975). 
Os resultados dos atributos químicos do solo, na área do experimento, antes do plantio e aos 270 dias após plantio (DAP), em função dos tratamentos e a análise química da cama-defrango semidecomposta utilizada no experimento, são apresentados na Tabela 1. No dia anterior ao do plantio foi feita a distribuição da cama-defrango a ser incorporada, nas parcelas e doses correspondentes. Imediatamente após foi feita a passagem do rotocanteirador, para a incorporação uniforme.

Para o plantio, foram utilizados rebentos de plantas do clone de mandioquinha-salsa 'Amarela de Carandaí', cultivadas na região de Manhuaçu-MG. Os rebentos foram destacados das coroas com um dia de antecedência ao do plantio, selecionados, classificados visualmente e separados em grupos de quatro tamanhos, sendo cada um deles com massas médias de 18,47 g, $13,52 \mathrm{~g}, 10,08 \mathrm{~g}$ e $6,23 \mathrm{~g}$. No dia do plantio, os rebentos foram preparados com o corte da parte aérea, deixando-se cerca de $2,0 \mathrm{~cm}$ de pecíolo, e com o corte transversal da parte basal. O plantio foi realizado manualmente, deixando descobertos os ápices dos rebentos (HEREDIA ZÁRATE et al., 2009) e imediatamente após o plantio, fez-se a distribuição da cama-de-frango em cobertura, nas parcelas correspondentes.

Para irrigação utilizou-se o sistema de aspersão, sendo que na fase inicial, até quando as plantas apresentavam entre $15 \mathrm{a} 20 \mathrm{~cm}$ de altura, os turnos de rega foram a cada dois dias e até os 180 dias, os turnos de rega foram a cada três dias, e posteriormente, até a colheita, as regas foram feitas uma vez por semana. O controle das plantas infestantes foi feito com enxada, entre os canteiros, e manualmente dentro dos canteiros. Não houve ocorrência de pragas e doenças.

Quando as plantas apresentaram em torno de $70 \%$ de senescência das folhas, o que ocorreu aos 270 dias após o plantio, efetuou-se a colheita e avaliaram-se as massas frescas e secas (massa obtida após a secagem do material em estufa com ventilação forçada de ar, até massa constante, à temperatura de $65^{\circ} \mathrm{C} \pm 2^{\circ} \mathrm{C}$ ) de folhas, rebentos, coroas, raízes comercializáveis (massa acima de 25 g) e não-comercializáveis (massas inferiores a $25 \mathrm{~g}$ e as danificadas). Também foram contados os números de rebentos, raízes comercializáveis e não-comercializáveis e feito o diâmetro e comprimento de raízes comercializáveis e nãocomercializáveis.

Os dados de produção foram submetidos à análise de variância para determinação do erro experimental da matriz. Para estimar as superfícies de resposta, foram ajustados os modelos quadrático e quadrático base raiz quadrada às médias por tratamento. Cada componente dos modelos foi testado até $5 \%$ de probabilidade, pelo teste $\mathrm{F}$, utilizando-se o quadrado médio do erro experimental da matriz. Cada efeito individual do modelo escolhido foi testado até o nível de $5 \%$, pelo teste $\mathrm{F}$, corrigido em função do erro experimental, usando t calculado pelo programa estatístico SAEG (RIBEIRO JÚNIOR; MELO, 2009). 


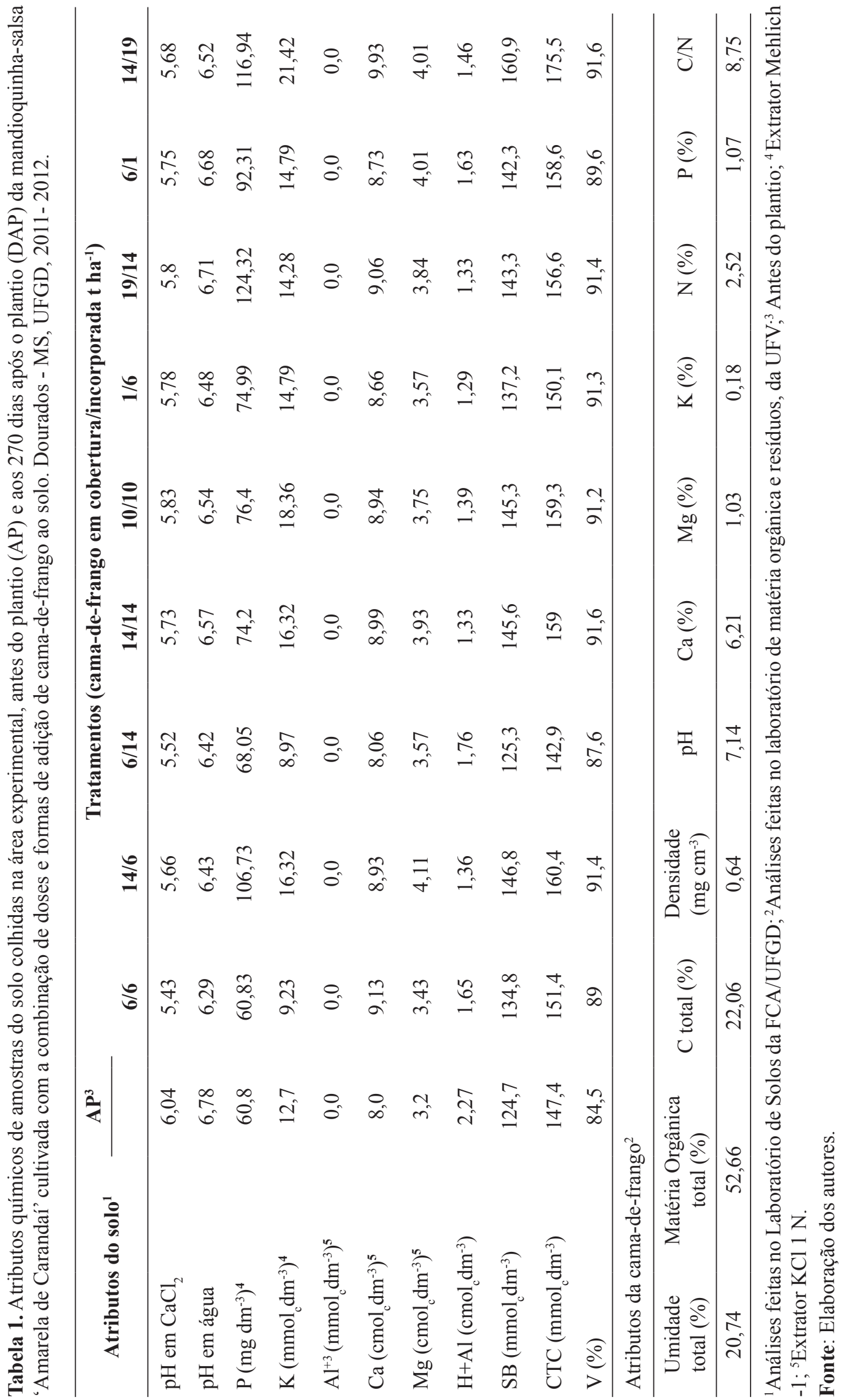


Os custos de produção foram calculados utilizando-se tabelas adaptadas de Terra et al. (2006). Para a renda líquida, foram utilizados as produções de massa fresca de raízes comercializáveis e o preço pago ( $\mathrm{R} \$ 2,50)$ por cada quilograma de raiz de mandioquinha-salsa na feira central de Dourados - MS, em março de 2012, segundo dados apresentados por Torales (2012). Para determinar o custo da mão-de-obra foi considerada a quantidade de dias/homem gastos para a realização de cada trabalho multiplicado pelo valor diário pago em Dourados-MS para a mão-de-obra temporária (R\$ $35,00 \mathrm{D} / \mathrm{H})$. O custo com maquinários incluindo bomba de irrigação e trator foi efetuado pelo registro das horas utilizadas para a realização dos trabalhos necessários em cada operação. Posteriormente, fezse a conversão para hora/máquina por hectare e multiplicou-se pelo valor em horas de uso de cada maquinário. Para determinar o custo das mudas, foi calculada a quantidade de mudas utilizadas e posteriormente multiplicada pelo preço de $\mathrm{R} \$ 2,00$ $\mathrm{kg}^{-1}$ pago ao produtor (SANTOS, 2011).

A renda bruta foi determinada pela multiplicação da produtividade média de mandioquinha-salsa de cada tratamento pelo preço pago ao produtor pelo quilograma de raízes comercializáveis. A renda líquida foi determinada pela renda bruta menos os custos de produção por hectare cultivado.

\section{Resultados e Discussão}

As massas frescas de folhas, coroas e raízes não-comercializáveis foram influenciadas significativamente pela interação doses e formas de adição da cama-de-frango. As maiores produtividades de folhas $\left(7,97 \mathrm{t} \mathrm{ha}^{-1}\right)$ e de coroas $\left(7,04 \mathrm{t} \mathrm{ha}^{-1}\right)$, foram obtidas nos tratamentos $19 \mathrm{C} \mathrm{e}$ 19 I (Figura 2a) e $19 \mathrm{C}$ e $1 \mathrm{I} \mathrm{t} \mathrm{ha}^{-1}$ (Figura 2b) de cama-de-frango, superando em 47,30 e 35,94\% aos menores valores obtidos, que foram de 4,20 e 4,51 t ha ${ }^{-1}$ com os tratamentos $6 \mathrm{C}$ e $1 \mathrm{I}$ e $6 \mathrm{C}$ e $14 \mathrm{I}$ $\mathrm{t} \mathrm{ha}^{-1}$, respectivamente. $\mathrm{O}$ provável efeito benéfico da cama-de-frango pode estar relacionado com os aumentos dos teores de $\mathrm{P}, \mathrm{K}$ e $\mathrm{Mg}$ (Tabela 1) que foram determinados na análise do solo realizado em amostras obtidas no final do ciclo de cultivo. Moreti et al. (2007) observaram elevação do P extraível em $78,25 \mathrm{mg} \cdot \mathrm{dm}^{-3}$ e K de $0,59 \mathrm{mmol}_{\mathrm{c}} \cdot \mathrm{dm}^{-3}$ do solo após aplicação de 14,0 t ha-1 de esterco de galinha em plantas de cobertura (crotalária e milheto).

Para massa fresca de raízes não-comercializáveis (Figura 2c), a maior produtividade $\left(4,72 \mathrm{t} \mathrm{ha}^{-1}\right)$ foi obtida com baixas doses $(0,39 \mathrm{C}$ e $0,13 \mathrm{It}$ ha$\left.{ }^{1}\right)$ de cama-de-frango. Esses resultados podem ser explicados pelo fato do solo ficar exposto as radiações solares, quando utilizou-se a cama-de-frango nas menores doses, elevando assim, a temperatura do solo e, consequentemente, danificando as raízes das plantas, aumentando as raízes não-comercializáveis. A cama-de-frango utilizada em cobertura induz a manutenção de temperaturas mais baixas em relação ao ambiente externo, o que, normalmente, melhora o equilíbrio hídrico/térmico e a capacidade fotossintética na planta (LARCHER, 2006).

A massa fresca de raiz comercializável não foi influenciada significativamente pelos fatores em estudo, obtendo o menor (16,34 $\left.\mathrm{t} \mathrm{ha}^{-1}\right)$ e maior $\left(22,08 \mathrm{t} \mathrm{ha}^{-1}\right)$ valor com o uso de $14 \mathrm{C}$ e $19 \mathrm{I} ; 19$ C e 14 I t ha $^{-1}$ de cama-de-frango, respectivamente. Esses valores podem ser considerados elevados quando comparadas com a média relatada por Torales et al. (2010) ao estudarem a mandioquinhasalsa 'Amarela de Carandaí', cultivada em solo com cinco doses de cama-de-frango adicionadas em cobertura $\left(0 ; 5 ; 10 ; 15\right.$ e $\left.20 \mathrm{t} \mathrm{ha}^{-1}\right)$ e com duas e três fileiras no canteiro $(60,0$ e $33,3 \mathrm{~cm}$ entre fileiras), que obtiveram maior produtividade $(14,00$ $\mathrm{t} \mathrm{ha}^{-1}$ ) com o uso de $20 \mathrm{t} \mathrm{ha}^{-1}$ e com Heredia Zárate et al. (2010), que testando a brotação e a produção da mandioquinha-salsa 'Amarela de Carandai', proveniente de mudas desinfectadas com óleo de eucalipto e enraizadas em bandejas com colheita aos 264 DAP, obtiveram 9,60 tha ${ }^{-1}$. Essas diferenças produtivas obtidas na literatura podem associar-se as diferenças nos tratos culturais empregados. 
Figura 2. Massas frescas de folhas (a), de coroas (b) e de raízes não-comercializáveis (c) de plantas de mandioquinhasalsa 'Amarela de Carandai', cultivadas em solos com diferentes combinações de doses e formas de adição de camade-frango ao solo. Dourados - MS, UFGD, 2011- 2012.
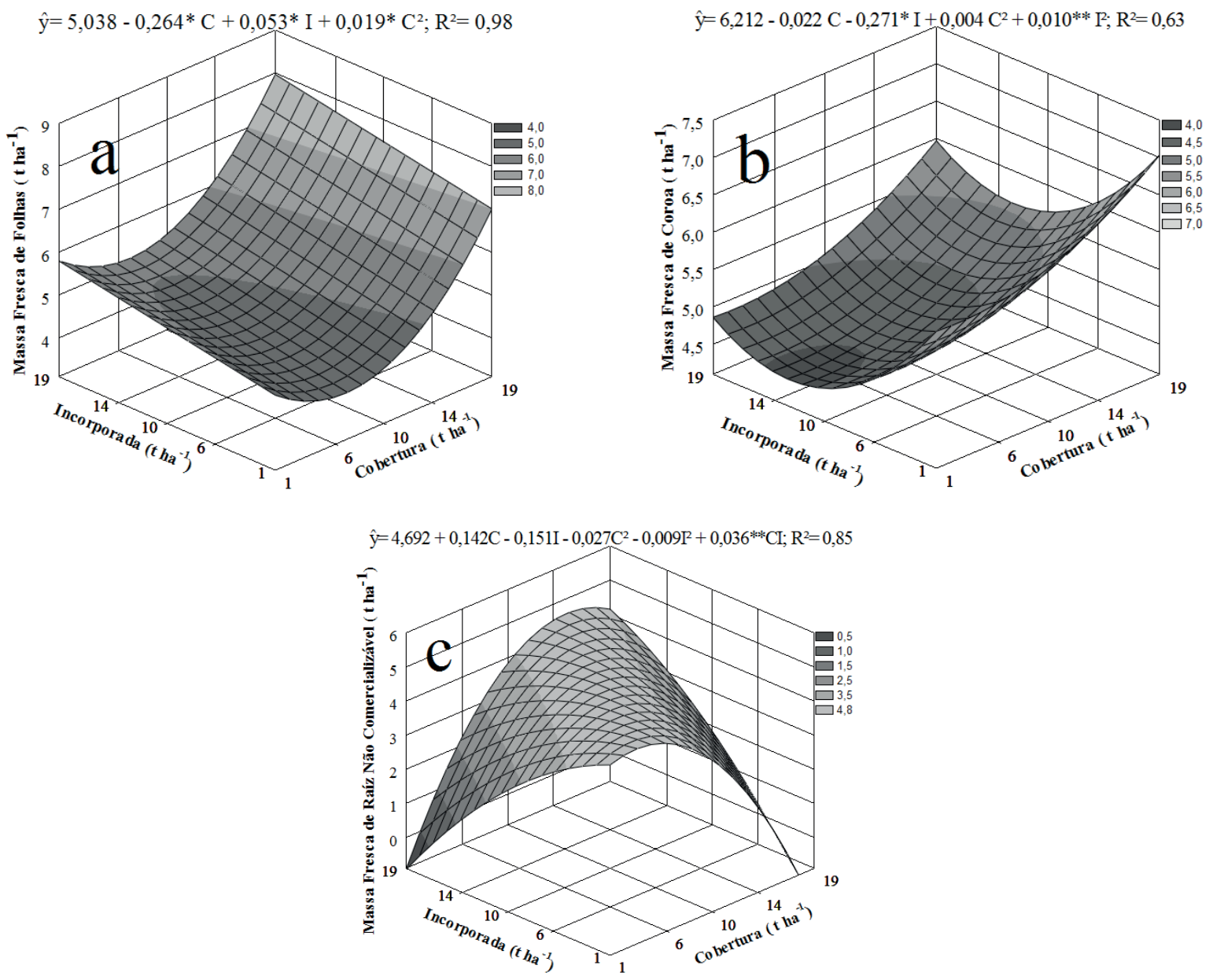

Fonte: Elaboração dos autores.

As altas produtividades de raízes sendo a combinação de $19 \mathrm{C}$ e $14 \mathrm{I} \mathrm{t} \mathrm{ha}^{-1}$ de camacomercializáveis e a falta de diferenças significativas entre os tratamentos aplicados de-frango a que obteve maior produtividade $(18,29$ neste trabalho podem ter relação direta com a alta fertilidade do solo onde o experimento foi conduzido, principalmente em relação aos valores de fósforo (P) (Tabela 1), elemento que interfere nos processos de fotossíntese, respiração, armazenamento e transferência de energia, divisão celular e crescimento das células, e contribui para o crescimento prematuro das raízes (TAIZ; ZEIGER, 2009).

A massa fresca de rebentos não se ajustou aos modelos quadrático e quadrático base raiz quadrada, $t \mathrm{th}^{-1}$ ), superando em $6,39 \mathrm{t} \mathrm{ha}^{-1}$ a combinação de 1 $\mathrm{C}$ e $6 \mathrm{I} \mathrm{t} \mathrm{ha}^{-1}$ (Figura 3). Acredita-se que a cama-defrango em doses mais elevadas na forma incorporada possa ter induzido mudanças na aeração e na capacidade de retenção de água, aumentando assim, a atividade dos processos microbianos no solo, em resposta à decomposição orgânica, que deve ter ocorrido em função do longo ciclo vegetativo da mandioquinha-salsa, favorecendo o crescimento e o desenvolvimento das plantas, enquanto que a camade-frango em cobertura propiciou a manutenção da temperatura e umidade do solo (KIEHL, 2010). 
Figura 3. Massas frescas de rebentos de plantas de mandioquinha-salsa 'Amarela de Carandai', cultivadas em solos com diferentes combinações de doses e formas de adição de cama-de-frango no solo. Dourados - MS, UFGD, 2011- 2012.

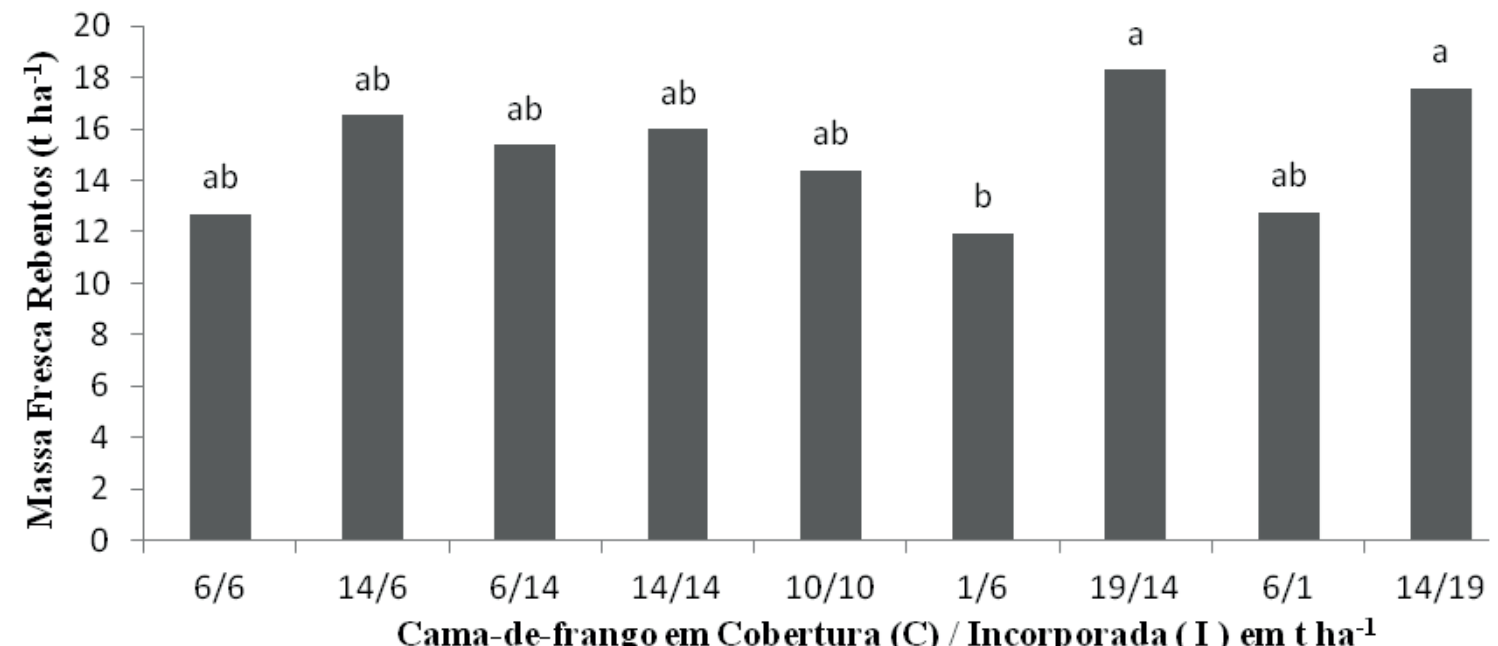

Fonte: Elaboração dos autores.

As massas secas de folhas e de coroas seguiram a mesma tendência de massa fresca, apresentando as maiores produtividades com as combinações de cama-de-frango $19 \mathrm{C}$ e $19 \mathrm{I}\left(1,22 \mathrm{t} \mathrm{ha}^{-1}\right)$ e $19 \mathrm{C}$ e 1 I $\left(1,34 \mathrm{t} \mathrm{ha}^{-1}\right)$, respectivamente (Figuras $4 \mathrm{a}$ e $4 \mathrm{~b}$ ). A maior produtividade de massa seca de rebentos $\left(4,01 \mathrm{tha}^{-1}\right)$ foi obtida com $19 \mathrm{C}$ e $1 \mathrm{I} \mathrm{tha}^{-1}$ de cama- de-frango, superando em 57,61\% ao menor valor obtido $\left(1,70 \mathrm{tha}^{-1}\right)$, que foi na dose de $1 \mathrm{C}$ e $1 \mathrm{I} \mathrm{t} \mathrm{ha}^{-1}$ de cama-de-frango (Figura 5a). Essa produtividade pode ter sido incrementada pela adição da cama-defrango em cobertura, que auxiliou disponibilizando nutrientes e mantendo a umidade do solo ao longo do ciclo da cultura, contribuindo para as maiores massas secas produzidas pelas plantas.

Figura 4. Massas secas de folhas (a) e de coroas (b) de plantas de mandioquinha-salsa 'Amarela de Carandai', cultivadas em solos com diferentes combinações de doses e formas de adição de cama-de-frango ao solo. Dourados MS, UFGD, 2011- 2012.
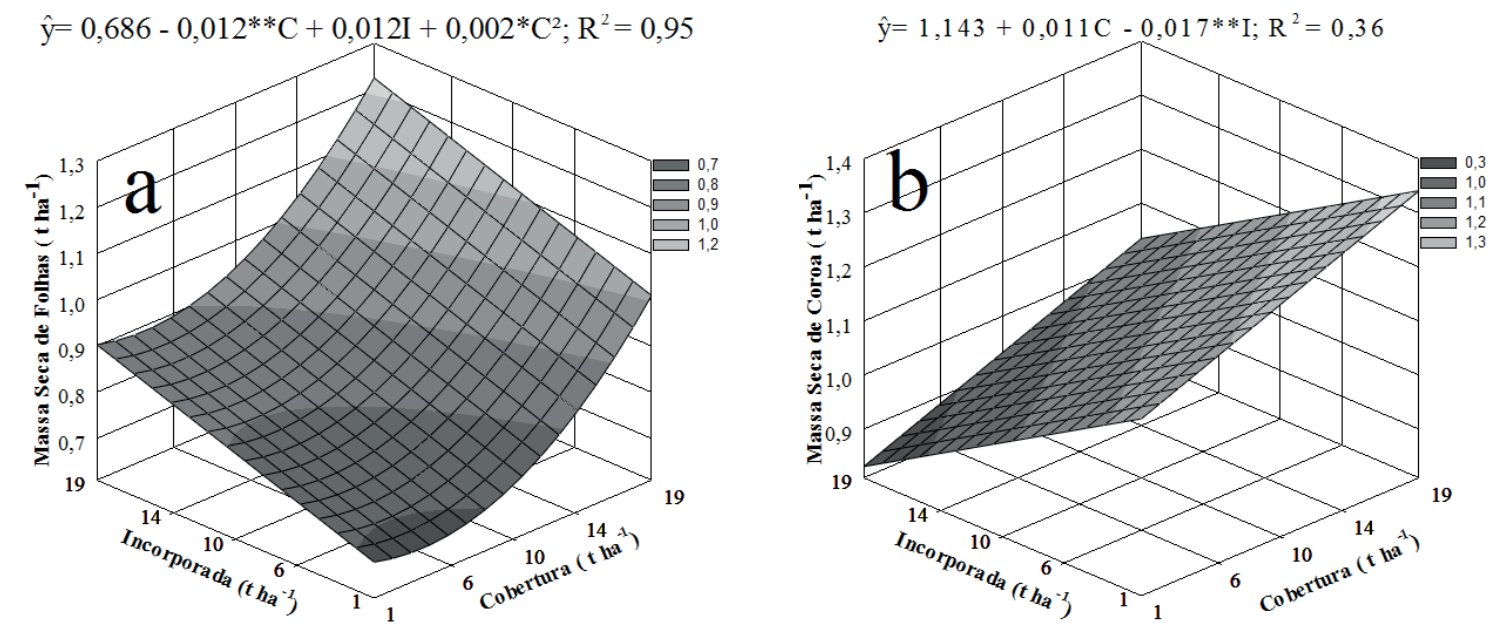

Fonte: Elaboração dos autores. 
Figura 5. Massas secas de rebentos (a) e de raízes não-comercializáveis (b) de plantas de mandioquinha-salsa 'Amarela de Carandai', cultivadas em solos com diferentes combinações de doses e formas de adição de cama-de-frango ao solo. Dourados - MS, UFGD, 2011- 2012.
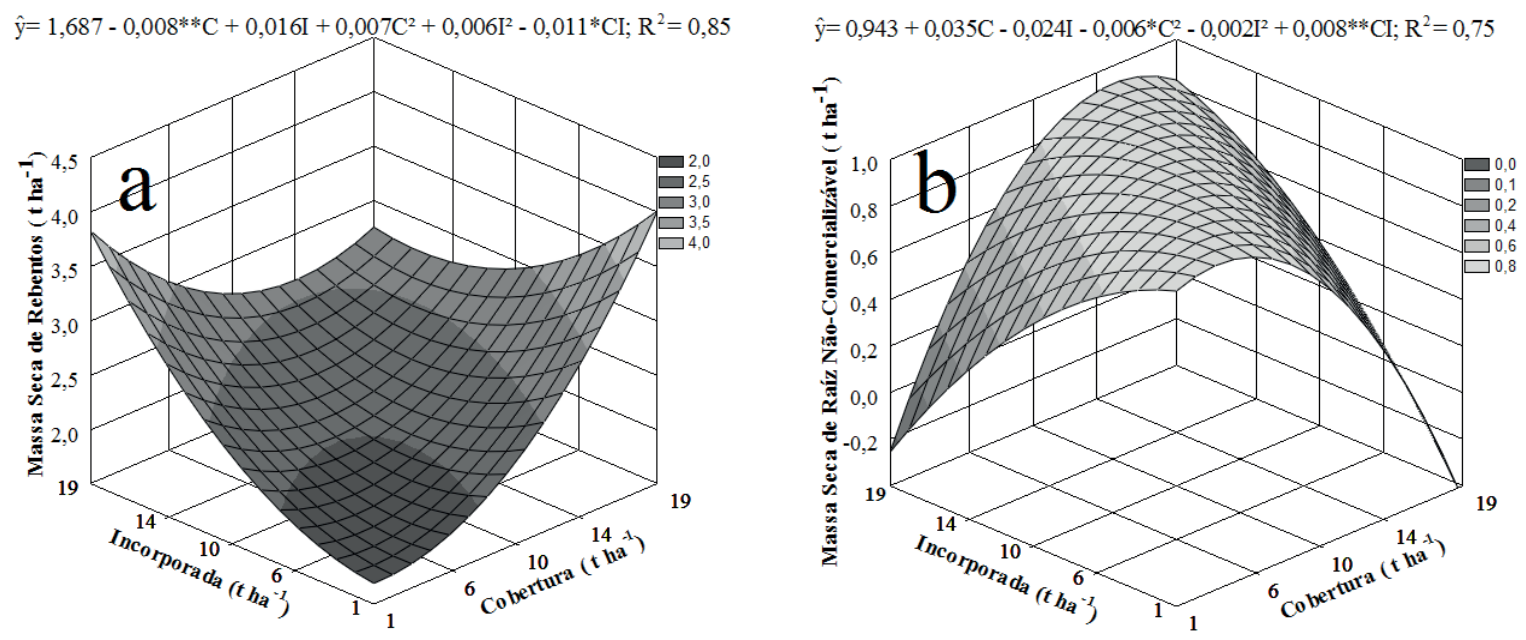

Fonte: Elaboração dos autores.

A massa seca de raízes não-comercializáveis apresentou a maior produtividade $\left(0,93 \mathrm{t} \mathrm{ha}^{-1}\right) \mathrm{com}$ 2,93 C e 4,82 I t ha-1 de cama-de-frango (Figura 5b). A massa seca de raízes comercializáveis não se ajustou aos modelos quadrático nem quadrático base raiz quadrada mantendo-se uma média de produtividade de 3,72 $\mathrm{t} \mathrm{ha}^{-1}$. Esses resultados demonstram que os sistemas vegetais têm mecanismos de auto-regulação, baseados na capacidade de adaptação do organismo individual e das populações ou no equilíbrio das relações de interferência (TAIZ; ZEIGER, 2009).

Os números de raízes comercializáveis e de rebentos foram influenciados significativamente pelos tratamentos, apresentando os maiores números de raízes comercializáveis com a utilização das maiores doses aplicadas em cobertura (617.240 ha-

1) ou incorporada $\left(600.830 \mathrm{ha}^{-1}\right)$ combinada com as doses mínimas, sendo elas 19 C e 1 I; 1 C e 19 I t ha $^{-1}$ de cama-de-frango, respectivamente (Figura 6a).

O número de raízes não-comercializáveis não se ajustou aos modelos quadrático nem quadrático base raiz quadrada e não foi influenciada significativamente pelos tratamentos isolados, mantendo uma média de raízes de 382.250 ha $^{-1}$. O número de rebentos (Figura 6b) foi influenciado significativamente pela combinação das doses em cobertura e incorporada, apresentando o maior número (946.460 ha-1) com as combinações 19,00 $\mathrm{C}$ e 12,32 I t ha ${ }^{-1}$. Estes resultados vão ao encontro do exposto por Larcher (2006), de que o padrão de resposta de uma planta e seu potencial específico de adaptação durante o seu período de crescimento é característica geneticamente determinada. 
Figura 6. Número de raízes comercializáveis (a) e rebentos (b) de plantas de mandioquinha-salsa 'Amarela de Carandai', cultivadas em solos com diferentes combinações de doses e formas de adição de cama-de-frango ao solo. Dourados - MS, UFGD, 2011- 2012.
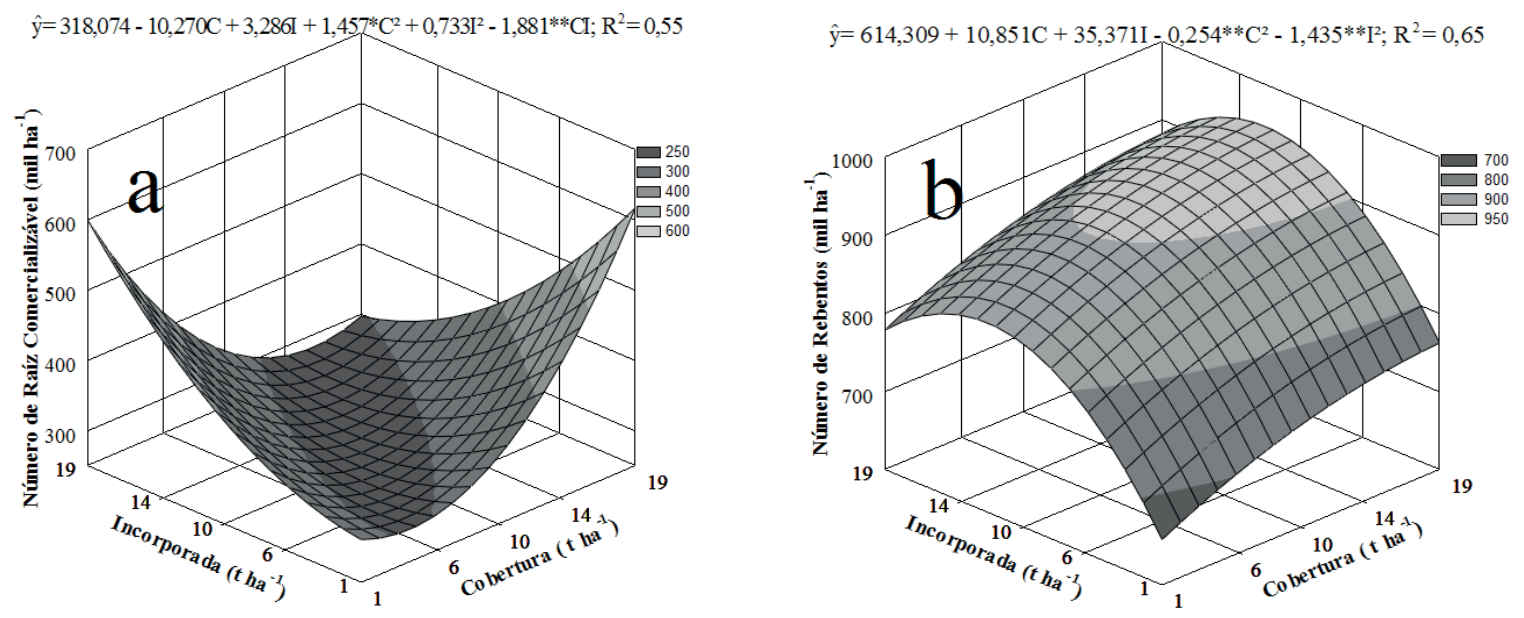

Fonte: Elaboração dos autores.

Os comprimentos e os diâmetros das raízes comercializáveis e não-comercializáveis de mandioquinha-salsa foram influenciados significativamente pela interação dos tratamentos (Figuras 7 e 8 ).
Embora o comprimento $(47,53 \mathrm{~mm})$ e diâmetro $(30,86 \mathrm{~mm})$ de raízes comercializáveis tenha sido menor com a utilização da combinação 19 C e 1 I t ha ${ }^{-1}$ de cama-de-frango (Figura $7 \mathrm{a}$ e $8 \mathrm{a}$ ), esses valores foram compensados com o número de raízes (Figura 6a).

Figura 7. Comprimento de raízes comercializáveis (a) e raízes não-comercializáveis (b) de plantas de mandioquinhasalsa 'Amarela de Carandai', cultivadas em solos com diferentes combinações de doses e formas de adição de camade-frango ao solo. Dourados - MS, UFGD, 2011- 2012.
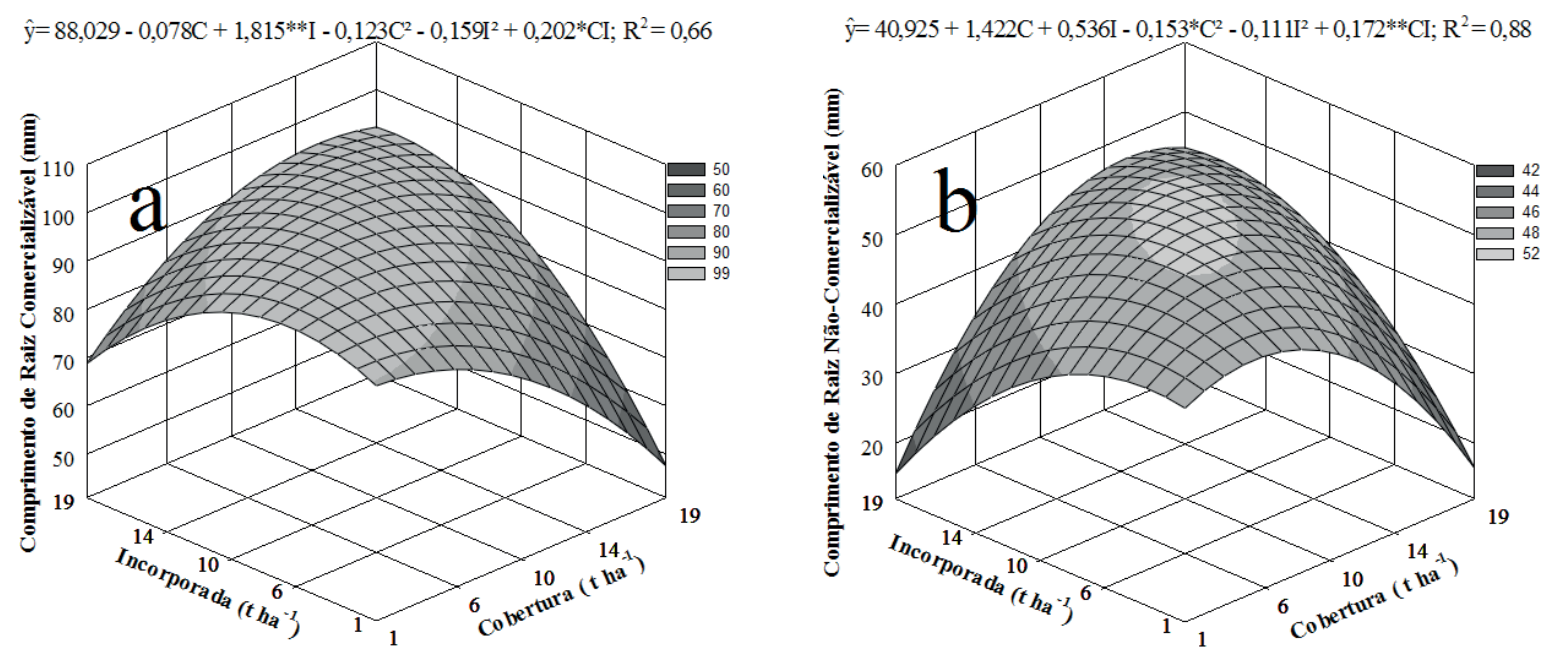

Fonte: Elaboração dos autores. 
Figura 8. Diâmetro de raízes comercializáveis (a) e raízes não-comercializáveis (b) de plantas de mandioquinha-salsa 'Amarela de Carandai', cultivadas em solos com diferentes combinações de doses e formas de adição de cama-defrango ao solo. Dourados - MS, UFGD, 2011- 2012.
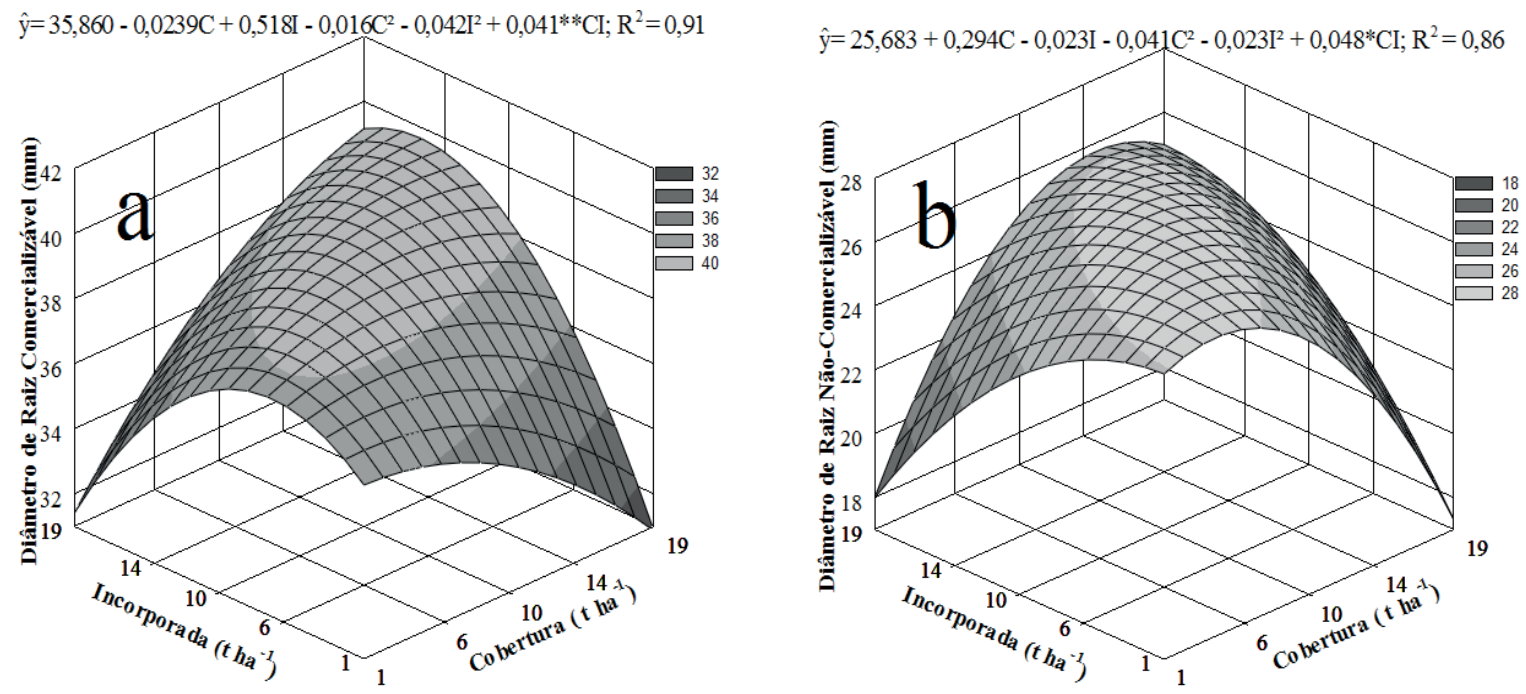

Fonte: Elaboração dos autores.

O maior comprimento de raízes comercializáveis $(98,16 \mathrm{~mm})$ foi obtido com a combinação da camade-frango nas doses de 9,19 $\mathrm{C}$ e 11,56 $\mathrm{I} \mathrm{t} \mathrm{ha}^{-1}$, superando em 50,37 $\mathrm{mm}$ ao menor valor obtido com o tratamento 19 C e 1 I t ha-1 (Figura 7a). Para raízes não-comercializáveis, o maior comprimento $(51,32$ $\mathrm{mm}$ ) foi com 10,61 C e 10,62 I t ha ${ }^{-1}$ superando em $35,00 \mathrm{~mm}$ ao menor valor obtido (16,32 $\mathrm{mm}$ ) com a combinação $19 \mathrm{C} \mathrm{e} 1 \mathrm{I} \mathrm{t} \mathrm{ha}^{-1}$ (Figura 7b). O diâmetro de raiz comercializável alcançou seu máximo $(39,66$ $\mathrm{mm}$ ) com a aplicação de $18,84 \mathrm{C}$ e $15,54 \mathrm{It} \mathrm{ha}^{-1}$ de cama-de-frango. Para raiz não-comercializável o valor máximo foi de 26,76 mm com 9,84 C e 10,66 I t ha-1 de cama-de-frango. Os menores diâmetros das raízes comercializáveis $(30,86 \mathrm{~mm})$ (Figura 8a) e não-comercializáveis (17,30 mm) (Figura 8b) foram obtidos com a combinação de $19 \mathrm{C}$ e $1 \mathrm{I}$ t ha $^{-1}$ de cama-de-frango. A incorporação da matéria orgânica no solo provoca uma intensa atividade dos microrganismos, fazendo com que as substâncias produzidas funcionem como elementos aglutinantes das partículas, melhorando a estruturação do solo (KIEHL, 2010) e assim as raízes desenvolveram-se melhor em comprimento e diâmetro.

Para se produzir 1,0 ha de mandioquinha-salsa com os tratamentos em estudo, os custos estimados variaram em $\mathrm{R} \$ 3.979,69$ entre o menor $(\mathrm{R} \$ 9.146,42)$ e maior $(\mathrm{R} \$ 13.126,11)$ custo, correspondentes aos tratamentos com a adição de 7 e 33 tha $^{-1}$ de cama-defrango, respectivamente. Essas variações de custos estão relacionadas principalmente com insumos e a mão-de-obra (Tabela 2).

Os custos variáveis representaram $76,39 \%(\mathrm{R} \$$ 6.986,78) para as combinações $1 / 6$ e $6 / 1 \mathrm{t} \mathrm{ha}^{-1}$ de cama-de-frango, que tiveram o menor custo de produção e 77,99\% (R\$ 10.236,78) para as combinações 19/14 e 14/19 tha-1 de cama-de-frango, que apresentaram os maiores custos de produção. Tendo com insumos e mão-de-obra, as variações de R \$ 2.340,00 e R \$ 910,00, respectivamente. Para insumos a diferença apresentada está relacionada às doses por hectare (que variaram de 7,00 a 33,00 tha ${ }^{-1}$ ), enquanto que para mão-de-obra, esta diferença esta na aplicação da cama-de-frango.

Os gastos com maquinários foram de $\mathrm{R} \$ 1310,00$ ha $^{-1}$ representando $14,32 \%$ para as combinações $1 / 6$ e $6 / 1 \mathrm{t} \mathrm{ha}^{-1}$ e $9,98 \%$ para as combinações $19 / 14$ e 14/19 t ha $^{-1}$ de cama-de-frango. 


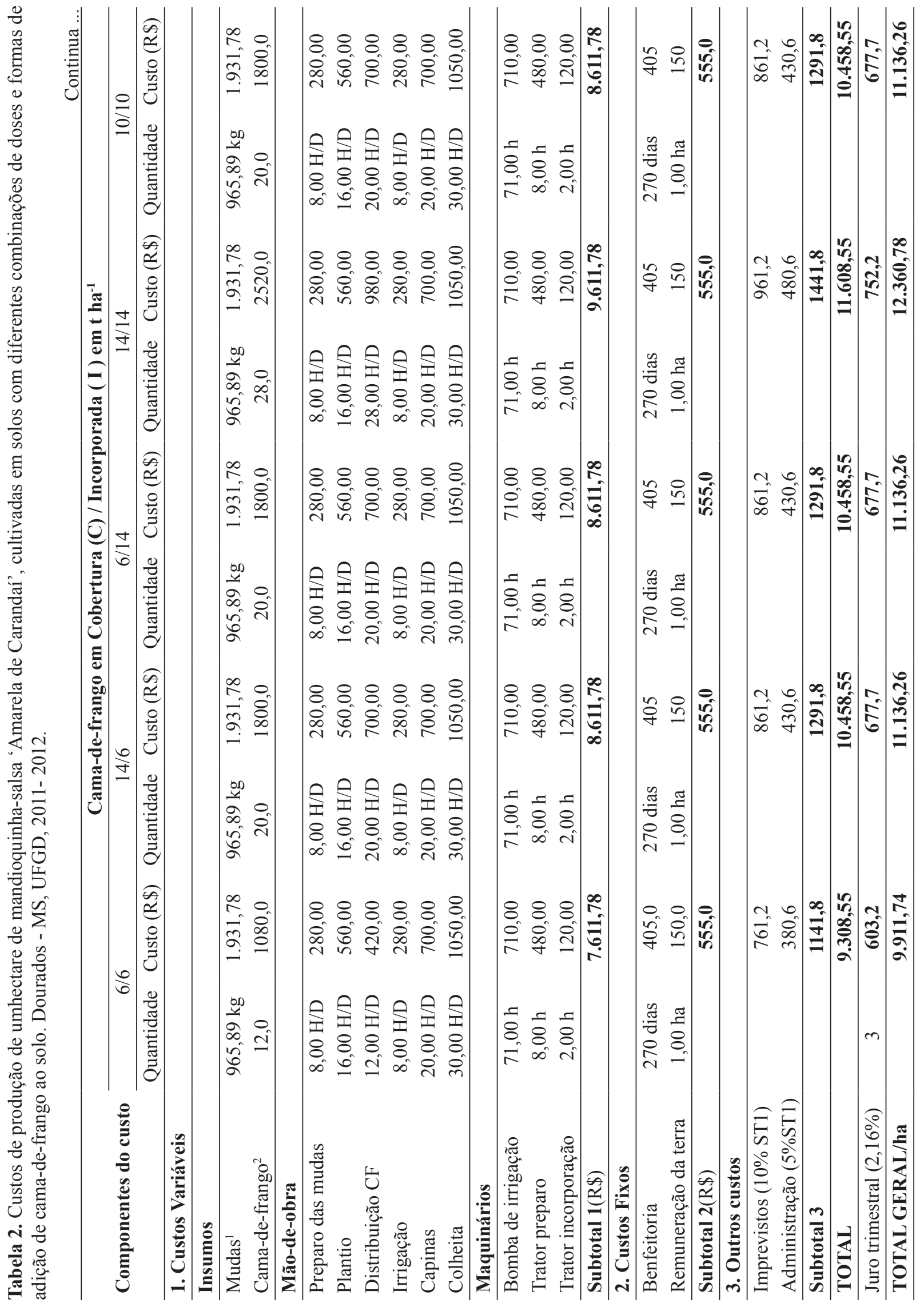




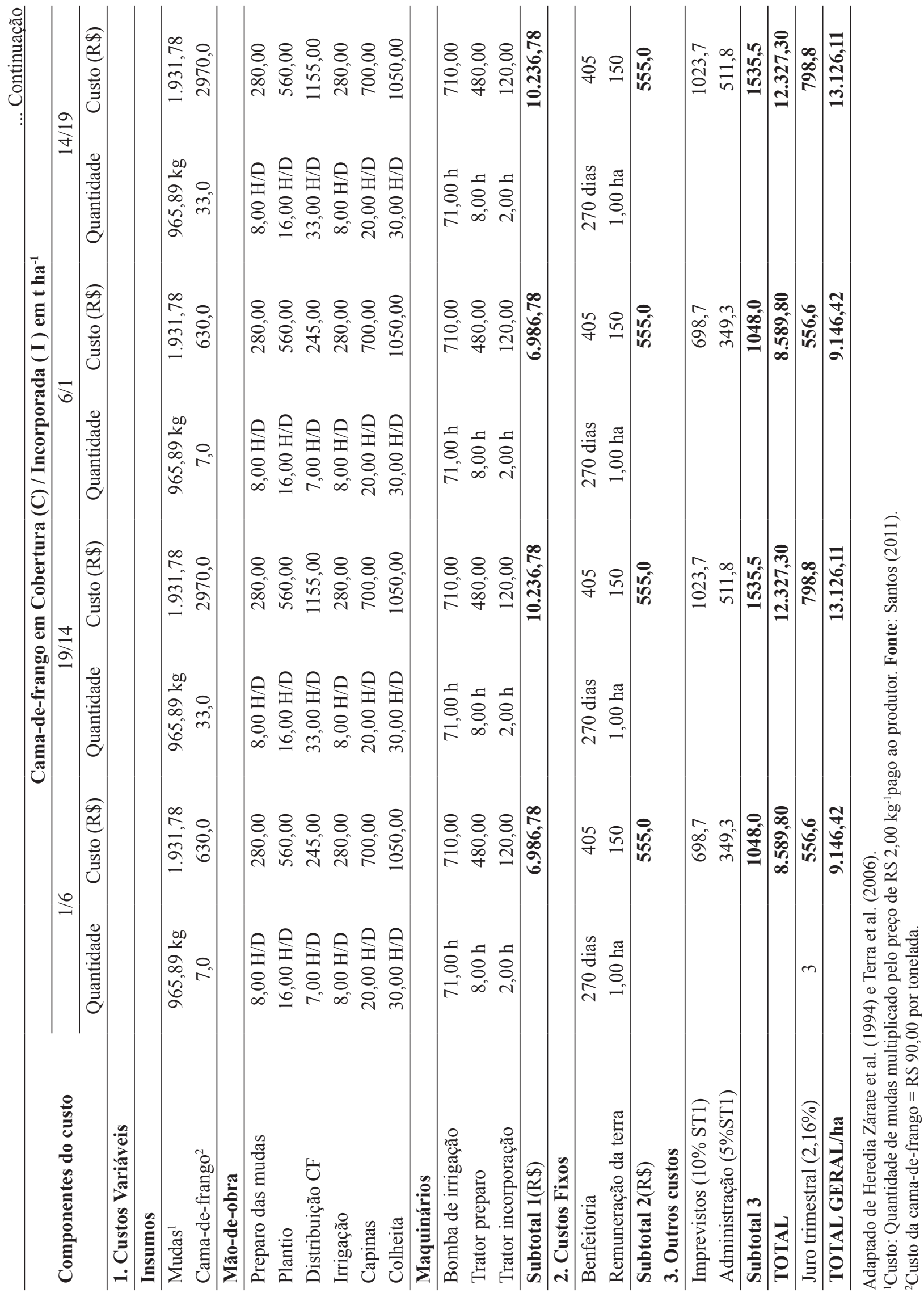


Considerando as médias de produtividade das raízes comerciais obtidas em cada tratamento e a estimativa das rendas bruta e líquida (Tabela 3), observou-se que o cultivo da mandioquinha-salsa 'Amarela de Carandaí' utilizando-se a cama-defrango na dose de $19 \mathrm{t} \mathrm{ha}^{-1}$ em cobertura e $14 \mathrm{tha}^{-1}$ incorporada, propiciou a maior produção de raízes comercializáveis $\left(22,08 \mathrm{t} \mathrm{ha}^{-1}\right)$, a maior renda bruta
( $\mathrm{R} \$ 55.187,60)$ e maior renda liquida $(\mathrm{R} \$ 42061,44)$, superando em 5,74 tha ${ }^{-1}$ de raízes comercializáveis, e $\mathrm{R} \$ 14.343,86$ às rendas bruta e líquida, em relação as obtidas com a utilização de $14 \mathrm{t} \mathrm{ha}^{-1}$ em cobertura e $19 \mathrm{t} \mathrm{ha}^{-1}$ incorporada, tratamento que obteve a menor produtividade de raízes comercializáveis $\left(16,34 \mathrm{tha}^{-1}\right)$, renda bruta $(\mathrm{R} \$ 40.843,70)$ e líquida $(\mathrm{R} \$ 27.717,58)$.

Tabela 3. Produtividade, renda bruta, custo de produção e renda líquida de raízes comercializáveis de mandioquinhasalsa 'Amarela de Carandaí', originadas da combinação de doses e formas de adição de cama-de-frango ao solo. Dourados - MS, UFGD, 2011- 2012.

\begin{tabular}{ccccc}
\hline $\begin{array}{c}\text { Cama-de-frango Cobertura(C) } \\
\text { e Incorporada (I) }\end{array}$ & $\begin{array}{c}\text { Produção } \\
\text { Comercial }\end{array}$ & Renda Bruta $^{1}$ & Custo de Produção $^{2}$ & Renda Líquida \\
\hline$\left(\mathrm{t} \mathrm{ha}^{-1}\right)$ & $\left(\mathrm{t} \mathrm{ha}^{-1}\right)$ & $\left(\mathrm{R} \$ \mathrm{ha}^{-1}\right)$ & $\left(\mathrm{R} \mathrm{ha}^{-1}\right)$ & $\left({\left.\mathrm{R} \$ \mathrm{ha}^{-1}\right)}^{-1}\right)$ \\
\hline 6,0 C e 6,0 I & 17,63 & 44064,90 & 9911,74 & 34153,16 \\
14,0 C e 6,0 I & 16,97 & 42421,50 & 11136,26 & 31285,24 \\
6,0 C e 14,0 I & 19,55 & 48863,90 & 11136,26 & 37727,66 \\
14,0 C e 14,0 I & 20,17 & 50421,90 & 12360,78 & 38061,16 \\
10,0 C e 10,0 I & 18,44 & 46091,90 & 11136,26 & 34955,66 \\
1,0 C e 6,0 I & 18,18 & 45452,10 & 9146,42 & 36305,72 \\
19,0 C e 14,0 I & 22,08 & 55187,60 & 13126,11 & 42061,44 \\
6,0 C e 1,0 I & 18,26 & 45653,90 & 9146,42 & 36507,43 \\
14,0 C e 19,0 I & 16,34 & 40843,70 & 13126,11 & 27717,58 \\
\hline
\end{tabular}

${ }^{1} \mathrm{R} \$ 2,50 \mathrm{~kg}^{-1}$. Preço pago pelo quilograma de mandioquinha-salsa na feira central em Dourados-MS (TORALES, 2012) ${ }^{2}$. Custo de produção de umhectare de mandioquinha-salsa 'Amarela de Carandaí'.

Fonte: Elaboração dos autores.

\section{Conclusões}

Nas condições em que foi desenvolvido o experimento concluiu-se que a combinação das doses e formas de aplicação da cama-de-frango possibilitaram o aumento da produtividade média de raízes comercializáveis e consequentemente o aumento da renda bruta e líquida. O cultivo da mandioquinha-salsa deve ser feito com adição ao solo de $19 \mathrm{t} \mathrm{ha}^{-1}$ em cobertura e $14 \mathrm{t} \mathrm{ha}^{-1}$ incorporada de cama-de-frango.

\section{Agradecimentos}

A CAPES, pela bolsa concedida, ao CNPq e à
FUNDECT, pelo apoio financeiro.

\section{Referências}

BUENO, S. C. S. Produção de mandioquinhasalsa (Arracacia xanthorrhiza Bancroft) utilizando diferentes tipos de propágulos. 2004. Tese (Doutorado em Agronomia) - Escola Superior de Agricultura Luiz de Queiroz, Universidade de São Paulo, Piracicaba.

EMPRESA BRASILEIRA DE PESQUISA AGROPECUÁRIA - EMBRAPA. Cento Nacional de Pesquisa de Solos. Sistema brasileiro de classificação de solos. Brasília: Embrapa Produção de informação. Rio de Janeiro: Embrapa Solos, 1999. $412 \mathrm{p}$. 
HEREDIAZÁRATE, N. A.; SCHWAN-ESTRADA, K. R.; VIEIRA, M. C.; HELMICH, M.; MACEDO, R. V.; HEID, D. M. Brotação e produção de mandioquinha-salsa 'Amarela de Carandaí', proveniente de mudas desinfectadas com óleo de eucalipto e enraizadas em bandejas. Bragantia, São Paulo, v. 69, n. 4, p. 871-875, 2010.

HEREDIA ZÁRATE, N. A.; VIEIRA, M. C.; GRACIANO, J. D.; FIGUEIREDO, P. G.; BLANS, N. B.; CURIONI, B. M. Produtividade de mandioquinha-salsa sob diferentes densidades de plantio e tamanho de mudas. Ciência $e$ Agrotecnologia, Lavras, v. 33, n. 1, p. 139-143, 2009.

HEREDIAZÁRATE, N. A.; VIEIRA, M. C.; RECH, J.; QUAST, A.; PONTIM, B. C. A.; GASSI, R. P. Yield and gross income of arracacha in monocrop and intercropping with the Japanese bunching onion and parsley. Horticultura Brasileira, Brasília, v. 26, n. 1, p. 277-281, 2008.

HEREDIA ZÁRATE, N. A.; CASALI, V. W. D.; ALVAREZ VENEGAS, V. H. Rentabilidade das culturas de inhame 'Macaquinho' e 'Chinês', em cinco populações e cinco épocas de colheita. In: ENCONTRO NACIONAL SOBRE A CULTURA DO INHAME, 1994. Anais... Viçosa: UFV, 1994, V. 1, p. 23-26.

HERMANN, M. Arracacha (Arracacia xanthorrhiza Bancroft). Andean roots and tubers: ahipa, arracacha, maca and yacon: promoting the conservation and use of underutilized and neglected crops. Gatersleben: IPGRI, 1997. 172 p.

KIEHL, E. J. Novos fertilizantes orgânicos. Piracicaba: Editora Degaspari, 2010. 248 p.

KINUPP, V. F.; LORENZI, H. Plantas alimentícias não convencionais (PNAC) no Brasil. São Paulo: Editora Instituto Plantarum, 2014. 768 p.

LARCHER, W. Ecofisiologia vegetal. São Carlos: Rima-Artes e Textos, 2006. 531 p.

MADEIRA, N. R.; SOUSA, R. J. Mandioquinhasalsa: alternativa para o pequeno produtor. Lavras: Editora UFLA, 2004. 71 p.

MELO, A. S.; COSTA, B. C.; BRITO, M. E. B.; AGUiAR NETTO, A. O. A.; VIÉGAS, P. R. A. Custo e rentabilidade na produção de batata-doce nos perímetros irrigados de Itabaiana, Sergipe.
Pesquisa Agropecuária Tropical, Goiânia, v. 39, n. 2, p. 119-123, 2009.

MORETI, D.; ALVES, M. C.; VALÉRIO FILHO, W. V.; CARVALHO, M. P. Atributos químicos de um latossolo vermelho sob diferentes sistemas de preparo, adubações e plantas de cobertura. Revista Brasileira de Ciência do Solo, Viçosa, MG, v. 31, n. 1, p. 167-175, 2007.

OLIVEIRA, F. L.; GUERRA, J. G. M.; ALMEIDA, D. L.; RIBEIRO, R. L. D.; SILVA, E. E. S.; SILVA, V. V.; ESPINDOLA, J. A. A. Desempenho de taro em função de doses de cama de aviário, sob sistema orgânico de produção. Horticultura Brasileira, Brasília, v. 26, n. 2, p. 149-153, 2008.

PEEL, M. C.; FINLAYSON, B. L.; McMAHON, T. A. Updated world map of the Köppen-Geiger climate classification. Hydrology and Earth System Sciences, Victoria, v. 11, n. 4, p 1633-1644, 2007.

RIBEIRO JÚNIOR, J. I.; MELO, A. L. P. Guia prático para utilização do SAEG. Viçosa: UFV, 2009. $287 \mathrm{p}$.

SANTOS, M. C. Produção agroeconômica de mandioquinha-salsa e cravo-de-defunto em cultivos solteiro e consorciado. 2011. Dissertação (Mestrado em Produção Vegetal) - Universidade Federal da Grande Dourados, Dourados.

SILVA, V.; ANEFALOS, L. C.; REIS FILHO, J. C. G. Indicadores de competitividade internacional dos produtos agrícolas e agroindustriais brasileiros, 1986-1998. Agricultura de São Paulo, São Paulo, v. 48, n. 1, p. 69-87, 2001.

TAIZ, L.; ZEIGER, E. Fisiologia vegetal. Porto Alegre: Artmed, 2009. 820 p.

TERRA, E. R.; HEREDIA ZÁRATE, N. A.; VIEIRA, M. C. MENDONÇA, P. S. M. Proposta de cálculo e forma de adubação, com e sem amontoa, para a produção e renda do milho Superdoce 'Aruba'. Acta Scientiarum: Agronomy, Maringá, v. 28, n. 1, p. 75-82, 2006.

TORALES, E. P. Cama-de-frango e espaçamentos entre plantas na produção agroeconômica de mandioquinha-salsa (Arracacia xanthorrhiza Bancroft). 2012. Tese (Doutorado em Produção Vegetal) - Universidade Federal da Grande Dourados, Dourados. 
TORALES, E. P.; HEREDIA ZÁRATE, N. A.; TURRENT, A.; LAIRD, R. J. La matrizexperimental VIEIRA, S. C. H.; RESENDE, M. M.; SANGALLI, Plan Puebla, para ensayos sobre prácticas de C. M. S.; GASSI, R. P. Doses de cama-de-frango e producción de cultivos. Agrociencia, Texcoco, v. densidade de plantio na produção de mandioquinhasalsa Amarela de Carandaí. Semina: Ciências 19, n. 1, p. 117-143, 1975.

Agrárias, Londrina, v. 31, n. 1, p. 1165-1176, 2010. 